Bond University

Research Repository

\title{
Physical Fitness: Differences Between Initial Hiring to Academy in Law Enforcement Recruits Who Graduate or Separate from Academy
}

Lockie, Robert G.; Dawes, Jay; Orr, Rob Marc; Dulla, Joseph

Published in:

Work

DOI:

10.3233/WOR-213438

Licence:

Other

Link to output in Bond University research repository.

Recommended citation(APA):

Lockie, R. G., Dawes, J., Orr, R. M., \& Dulla, J. (2021). Physical Fitness: Differences Between Initial Hiring to Academy in Law Enforcement Recruits Who Graduate or Separate from Academy. Work, 68(4), 1081-1090. https://doi.org/10.3233/WOR-213438

\section{General rights}

Copyright and moral rights for the publications made accessible in the public portal are retained by the authors and/or other copyright owners and it is a condition of accessing publications that users recognise and abide by the legal requirements associated with these rights.

For more information, or if you believe that this document breaches copyright, please contact the Bond University research repository coordinator 


\section{Physical Fitness: Differences between Initial Hiring to Academy in Law Enforcement Recruits Who Graduate or Separate from Academy}

\section{Brief Running Head: Physical Fitness Changes and Academy Separation}

Robert G. Lockie ${ }^{1}$, J. Jay Dawes ${ }^{2}$, Robin M. Orr ${ }^{3}$, Joseph M. Dulla ${ }^{3,4}$.

${ }^{1}$ Department of Kinesiology, California State University, Fullerton, Fullerton, CA, USA.

${ }^{2}$ School of Kinesiology, Applied Health and Recreation, Oklahoma State University, Stillwater, OK, USA.

${ }^{3}$ Tactical Research Unit, Bond University, Robina, Qld, Australia.

${ }^{4}$ Recruit Training Unit, Training Bureau, Los Angeles County Sheriff's Department, Los Angeles, CA, USA.

$凶$ Robert Lockie

California State University, Fullerton

Department of Kinesiology

800 N State College Blvd

Fullerton, CA 92831

USA

Phone (international): $\quad+1657-278-3316$

Email: $\quad$ rlockie@fullerton.edu

Key words: aerobic capacity, attrition, muscular endurance, occupational testing, police, tactical 


\begin{abstract}
BACKGROUND: Law enforcement agencies often include fitness testing as part of the hiring process. However, it can be months from this testing to when a recruit starts academy.

OBJECTIVE: To determine fitness changes from hiring to academy in recruits who graduate (GRAD) or separate (SEP; do not complete) from academy.

METHODS: Analysis on recruits from one agency, split into GRAD ( $n=436)$ and SEP ( $n=78)$ groups, was conducted. These tests were conducted during initial hiring and academy: push-ups, sit-ups, and arm ergometer revolutions in $60 \mathrm{~s}$; 75-yard pursuit run (75PR); and 2.4-km run. Data were analyzed via a two-way repeated measures ANOVA. Change scores were derived between hiring and academy data for both groups, and analyzed via independent samples t-tests.

RESULTS: Push-ups, 75PR, arm ergometer, and 2.4-km run generally improved $(p \leq 0.001)$. There were no significant between-group interactions or differences in performance changes for GRAD and SEP recruits. SEP recruits tended to have lesser fitness test performance compared to GRAD recruits.
\end{abstract}

CONCLUSIONS: GRAD and SEP recruits showed some fitness improvements between initial hiring through to academy. However, SEP recruits with lesser muscular endurance, running speed, and aerobic capacity during hiring did not substantially improve by academy, which likely impacted their academy survivability. 


\section{Introduction}

Law enforcement agencies (LEA) generally conduct academy training with their recruits, which is due to the physical [1-5] and mental $[6,7]$ challenges associated with policing. This training is used to ensure recruits have the physical and mental capacities to successfully complete the required tasks when on duty [8-11]. As a result of the physical challenges associated with both academy and the profession, many LEAs include fitness testing as part of the hiring process [1, 11]. These tests are designed to assess whether candidates have the capacity to graduate from academy $[11,12]$, and complete the necessary job tasks once they graduate $[13,14]$. Fitness testing can be one of the first stages of the hiring process $[15,16]$, which screens out less appropriate candidates. This is pertinent, as interviews, polygraph examinations, and medical and psychological evaluations can be time-consuming and expensive.

Due to the multi-tier hiring process of a recruit $[15,16]$, several months can elapse between the pre-hire fitness testing and the initial fitness testing at the start of training academy. Although recruits may pass minimum standards required for a LEA, this does not mean they are physically fit at the commencement of academy training. In the military, new officers have been found to lose fitness between their officer selection board and commencement of army officer training [17]. This could be problematic in law enforcement academy training. Studies have demonstrated that those recruits who do not complete academy tend to demonstrate lower levels of fitness as measured during week the preceding academy (slower 75-yard pursuit run [75PR] time, less shuttles completed in the 20-m multistage fitness test) [11] or in the first week of academy (less push-ups performed in $60 \mathrm{~s}$, slower 2.4-km run time) [12]. Tens of thousands of dollars are spent by a LEA during the hiring process [12], and the loss of recruits during academy can create further financial costs for an agency $[9,12]$. 
The pool of available recruits is getting smaller for many LEAs, due to changes in population demographics (i.e. there are less candidates who meet minimum physical fitness requirements) and skepticism about law enforcement as a profession [18, 19]. LEAs may end up with a wide disparity in fitness in their recruit classes [20-22], especially if their hiring standards are designed to allow for more candidates to potentially fill position shortages. This means that academy classes may feature recruits who have fitness levels that put them at greater risk of separation $[11,12]$. Furthermore, LEA staff cannot just assume that their fitter recruits at the start of the hiring process will remain that way by the time they start academy.

Certain agencies may conduct preparatory fitness training for candidates who are in the hiring process $[23,24]$. However, these are generally voluntary as candidates are not yet employees of the agency. This can make targeting those candidates who could benefit most from pre-academy fitness training difficult (i.e. those that demonstrate lower physical fitness that could put them at risk of separation), even though the provision of this type of service could assist with retention rates. Further, pre-academy fitness training programs are not always supervised by appropriately trained personnel, such as strength and conditioning coaches. This could influence the exercises that are programmed, especially for any lower-performing candidates or recruits. If a recruit demonstrates low physical fitness during the hiring process, and they do not improve prior to academy, this could increase their risk of separation $[11,12]$.

Therefore, the objective of this study was to demonstrate whether the physical fitness of law enforcement recruits who graduated (GRAD) or separated (SEP) changed from the start of the hiring process to the start of academy. SEP recruits were those who did not graduate from academy for any of a variety of reasons (e.g. personal reasons, physical training failures, injuries, academics, or scenario-based testing failures) [11]. It was hypothesized that recruits would improve their 
physical fitness from initial hiring to the start of academy. However, GRAD recruits would improve their fitness to a greater extent than the SEP recruits.

\section{Methods}

\subsection{Participants}

Data were collected by the staff of one LEA in the USA and was released with consent from that organization. A sample of convenience comprised of 514 recruits, which consisted of 417 males and 97 females, was analyzed. No control was placed on strength and conditioning practices or dietary interventions of individual recruits during the period prior to academy after their initial testing $[11,25,26]$. Based on the archival nature of this analysis, the institutional ethics committee approved the use of pre-existing data (HSR-17-18-370).

\subsection{Procedures}

The data in this study were collected by the staff of one LEA at two time points. The first time point was part of the initial hiring process before academy training. Fitness testing data from the hiring period was collected by agency staff over an approximate 12-18 month period. The collection of tests used by this agency were referred to as the Validated Physical Ability Test (VPAT) [27], and at the time comprised: maximum push-ups in $60 \mathrm{~s}$; maximum sit-ups in $60 \mathrm{~s}$; 75PR; maximum number of arm ergometer revolutions in $60 \mathrm{~s}$; and a 2.4-km run. The push-up and sit-up tests, 75PR, and arm ergometer test were conducted outdoors on concrete surfaces. The 2.4$\mathrm{km}$ run was performed on outdoor running tracks.

The second time point was the week preceding academy. As the human resources department within the LEA controlled when recruits were admitted to academy classes, the time 
period between fitness testing during hiring and academy could vary anywhere between 6-18 months for individual recruits. At the this second time point, agency staff administered a fitness assessment battery referred to as the VPAT + . Each recruit's age, height, and body mass were recorded during this session. Height was measured using a portable stadiometer (Seca, Hamburg, Germany), while body mass was recorded by electronic digital scales (Health o Meter, Neosho, Missouri). Testing typically occurred between 9:00am-2:00pm depending on recruit availability, and recruits typically did not eat in the $2-3$ hours prior to their testing session as they were completing employee-specific documentation for the LEA. Within the context of this study, data from push-up, sit-up, and arm ergometer tests, in addition to the 75PR, were considered in this analysis. All tests were conducted outdoors on concrete surfaces at the LEA's training facility.

The 2.4-km run was not conducted as part of the VPAT+. Thus, in order to provide comparative data to the $2.4-\mathrm{km}$ run completed during the VPAT, the academy $2.4-\mathrm{km}$ run time was taken from a fitness battery referred to as the PT500 which was completed in the first week of academy [10]. This run was completed outdoors on a dirt athletics track at the LEA's training facility, and typically between the hours of 6:00am-9:00am.

\subsection{VPAT}

The procedures for the tests conducted in the VPAT have been described [11, 25], but will be detailed here. These procedures were required to be uniform for all candidates (the term 'candidate' is used here as the individuals are not yet recruits to the LEA).

Push-ups: The push-up test assessed upper-body endurance. Candidates started in the 'up' position, with the body taut and straight, hands positioned approximately shoulder-width apart, and the fingers pointed forwards. During this phase of testing, this LEA required candidates to use 
a standard water bottle placed on its side to determine the bottom position of the push-up, which was placed underneath the candidate's chest [21]. On the start command, a staff member began the stopwatch, and candidates lowered themselves until their chests contacted the water bottle and extended their elbows to return to the start position. Candidates performed as many push-ups as possible using this technique within $60 \mathrm{~s}$.

Sit-ups: The sit-up test assessed abdominal muscular endurance. Candidates laid on their backs on padded mats with their knees flexed to $90^{\circ}$, heels flat on the ground, arms crossed across the chest, and hands positioned on the shoulders. The feet were held to the ground by a staff member. On the start command, candidates raised their shoulders from the ground while keeping their arms crossed and touched the elbows to the knees. The candidate then descended back down until the shoulder blades contacted the ground. Candidates completed as many repetitions as possible using this technique within $60 \mathrm{~s}$.

75PR: The 75PR was designed to simulate a foot pursuit $[13,21,25]$, and is shown in Figure 1. The candidate completed five linear sprints about a square grid, while completing four, $45^{\circ}$ direction changes to zig-zag across the grid. During three of the linear sprints, candidates also stepped over three barriers simulating curbs that were $2.44 \mathrm{~m}$ long and $0.15 \mathrm{~m}$ high. $75 \mathrm{PR}$ time was recorded via stopwatch by a staff member [13, 21, 25]. Timing commenced from the initiation of movement at the start of the sprint, and stopped when the candidate crossed the finish line.

***INSERT FIGURE 1 ABOUT HERE***

Arm Ergometer: This test was used as an assessment of upper-body endurance, and was performed on an arm ergometer (Monark 881E, Vansbro, Sweden) positioned on a table. The 
candidate knelt on a padded mat in a position so that the crankshaft handle was level with the candidate's shoulder. The test began from a position where the left arm of the candidate was fully extended and parallel to the ground. The candidate completed 10 revolutions of the arm ergometer prior to the test to set the resistance at 50 watts, and the counter was set to zero before the test commenced $[11,25]$. After the LEA staff member initiated the test, candidates completed as many revolutions as possible in $60 \mathrm{~s}$.

2.4-km Run: The $2.4 \mathrm{~km}$ run was used to assess aerobic capacity [28], and performed on a 400-m running track. Candidates completed six laps around the track as quickly as possible. The run time was recorded for each candidate on a handheld stopwatch to the nearest $0.10 \mathrm{~s}[11,25]$.

\subsection{VPAT+}

The procedures for the VPAT+ tests have also been previously detailed [11, 25]. The same methods for all VPAT tests were also adopted for the VPAT+, with one exception for the pushups. Rather than a water bottle, recruits performed the push-ups with a partner using their fist to indicate the bottom position of the push-up $[11,25]$. Although the different methodologies provide a limitation to this study, any differences between the height of the standard water bottle placed on its side and an adult fist were negligible as the water bottle is used to represent an adult fist height. Thus, the push-up data from the VPAT to the VPAT+ were still appropriate for comparison.

\subsection{4-km Run (PT500)}

As noted, the 2.4-km run was performed during the first week of academy and was overseen by the training staff from each academy class, with time recorded by a stopwatch [10, 29]. It should be noted that the intensity of the $2.4-\mathrm{km}$ run performed during initial hiring versus 
that performed in academy may have been different, as the training staff would provide strong verbal commands to the recruits during academy [7]. This could induce additional stress to some recruits which may affect running performance. Nonetheless, this run still provides context for comparison to the $2.4-\mathrm{km}$ run measured in the VPAT.

\subsection{Statistical Analysis}

Information as to whether recruits graduated from academy were provided by LEA staff [11], which was used to split recruits into two groups (GRAD and SEP). Descriptive statistics (mean \pm standard deviation $[\mathrm{SD}]$ ) were calculated for each variable. Independent samples t-tests $(p<0.05)$ were used to compare the age, height, and body mass of the GRAD and SEP recruits (all combined, and males and females separately). When analyzing any fitness differences between hiring to academy, sexes were combined within the GRAD and SEP groups [11]. Data were analyzed via a two-way repeated measures ANOVA $(p<0.05)$, including group as a betweensubjects factor measured at two levels (GRAD and SEP) [30]. The within-subject factor (time) represented the initial hiring (pre) and academy (post) fitness measures. As only two repeated measures were employed, the assumption of Mauchly's test of sphericity was not applicable. All other repeated measures ANOVA assumptions were considered, with the Levene's statistic used to determine homogeneity of variance. If a significant $F$ ratio was detected, post hoc analysis were performed using the Bonferroni adjustment procedure.

Change scores were calculated for each fitness variables from hiring to academy within each group [8]. Independent samples t-tests $(p<0.05)$ calculated any significant differences between the change scores for the groups. Effect sizes (Cohen's $d$ ) were also calculated from the difference between the means divided by the pooled standard deviations for the initial hiring and 
academy test results for the GRAD and SEP groups. A $d$ less than 0.2 was considered a trivial effect; 0.2 to 0.6 a small effect; 0.6 to 1.2 a moderate effect; 1.2 to 2.0 a large effect; 2.0 to 4.0 a very large effect; and 4.0 and above an extremely large effect [31]. All statistical analyses were computed using the Statistics Package for Social Sciences (Version 25.0; IBM Corporation, New York, USA) and Microsoft Excel (Microsoft Corporation ${ }^{\mathrm{TM}}$, Redmond, Washington, USA).

\section{Results}

Age, height, and body mass data for the GRAD and SEP recruits is shown in Table 1. When considering the data for both sexes combined, equal variances were assumed for height $(F=0.042$, $p=0.838)$, but not age $(F=58.066, p<0.001)$ and body mass $(F=4.463, p=0.035)$. SEP recruits were significantly older $(p<0.001)$ and lighter $(p=0.018)$ than GRAD recruits, with no significant differences in height $(p=0.084)$. When the sexes were analyzed separately, equal variances were not assumed for age for both male $(F=42.583, p<0.001)$ and female $(F=9.955, p=0.159)$ recruit groups. Equal variances were assumed for height (males: $F=0.460, p=0.498$; females: $F$ $=1.341, p=0.250$ ) and body mass (males: $F=2.212, p=0.138$; females: $F=2.335, p=0.130$ ). The SEP males were significantly $(p<0.001)$ older than the GRAD males; there were no significant differences in height $(p=0.441)$ or body mass $(p=0.391)$. There were no significant differences between the GRAD and SEP females for age $(p=0.159)$, height $(p=0.486)$, or body $\operatorname{mass}(p=0.096)$.

\footnotetext{
***INSERT TABLE 1 ABOUT HERE***
} 
Table 2 displays the data from fitness testing during the initial hiring process and at the start of academy for GRAD and SEP recruits. It should be noted that the sample size for the SEP recruits was 78 for the push-up, sit-up, 75PR, and arm ergometer. For the 2.4-km run, the sample size was 50 as 28 recruits had already separated from academy before this test was conducted. The Levene's statistic based on mean data indicated that data were homogenous for all variables $(p=$ 0.067-0.788). There were no significant interactions when considering time $\times$ group $(F=0.008-$ $2.310, p=0.129-0.928)$. For all variables, there were significant interactions for time. Push-up repetitions $(F(1,512)=10.918, p=0.001)$, 75PR time $(F(1,511)=26.529, p<0.001)$, arm ergometer revolutions $(F(1,504)=13.376, p<0.001)$, and 2.4-km run time $(F(1,480)=53.464, p$ $<0.001)$ improved, while the number of sit-up repetitions decreased $(F(1,511)=86.807, p<$ $0.001)$. GRAD recruits were significantly $(p \leq 0.030)$ superior to SEP recruits in all tests from initial hiring and academy.

\section{***INSERT TABLE 2 ABOUT HERE***}

With regards to the differences in variables from hiring to academy (Table 3), equal variances were assumed for all variables $(F=0.031-2.085, p=0.149-0.861)$. There were no significant differences in the change in any fitness variables from hiring to academy between the GRAD and SEP groups ( $p=0.129-0.881)$. For the GRAD recruits, there was a trivial effect for the increase in push-up repetitions, small effects for the decrease in 75PR time and increase in arm ergometer revolutions, and moderate effects for the decrease in sit-up repetitions and 2.4-km run time from hiring to academy. Regarding the SEP recruits, there were trivial effects for the increase 
in push-up repetitions and arm ergometer revolutions, and decrease in 75PR time; small effect for the decrease in 2.4-km run time; and moderate effect for the decrease in sit-up repetitions.

\section{***INSERT TABLE 3 ABOUT HERE***}

\section{Discussion}

This study investigated changes in fitness from initial testing during the hiring process to the start of academy in law enforcement recruits who graduated (GRAD) or separated (SEP) from academy. Pope et al. [32] has noted the pre-enlistment fitness (measured by the 20-m multistage fitness test) could be used to identify Australian Army recruits at-risk of attrition; initial hiring fitness data could be used by LEAs to ensure that those entering training sufficiently fit enough to complete training and enter the workforce. The characteristics of the subjects in this study, and the ratio between the sexes, was typical of law enforcement research $[10,13,21,25,26]$, which highlights the applicability of this data. GRAD and SEP recruits showed trivial-to-moderate improvements in push-ups, 75PR, arm ergometer, and the $2.4-\mathrm{km}$ run, and moderate decrements in sit-ups. There were no between-group differences in the change in performance for GRAD or SEP recruits which was contrary to the study hypotheses. This highlighted that (a) fitter recruits during the hiring process tended to remain that way through to academy, and (b) less fit recruits tended not to greatly improve their fitness despite this potentially decreasing their risk of academy separation and future employability in the profession.

The SEP recruits were older than GRAD recruits when both sexes were combined, and for the males as well. Although reasons for separation were not provided in the data sets for this study, Lockie et al. [11] did find that recruits who separated from academy for academic or scenario 
failures tended to be older. Older recruits can often present with lower fitness levels compared to their younger counterparts. For example, recruits 35 years of age or older demonstrated reduced upper- and lower-body power, as measured by a seated medicine ball throw and vertical jump test, respectively [26]. Lower levels of fitness can also increase the risk of injury in law enforcement recruits $[11,33,34]$, which can lead to academy separation. As stated, although reasons for separation were not analyzed in this study, there are still important issues that can be addressed specific to older recruits. Lockie et al. [26] recommended older individuals should complete specific training prior to academy. This proposition is reinforced when considering some of the fitness test data, and any changes that occurred from hiring to academy.

Shusko et al. [12] and Lockie et al. [11] indicated the importance of aerobic fitness for academy graduation in law enforcement recruits, as measured by the $2.4-\mathrm{km}$ run and $20-\mathrm{m}$ multistage fitness test, respectively. Both the GRAD and SEP recruits improved their performance in the 2.4-km run from hiring to academy, although the GRAD recruits had a moderate effect versus the small effect for the SEP recruits. The LEA in this study tends to have a training model that features a high running volumes [11,29]. This would place greater importance for recruits to have higher aerobic fitness and the capacity to complete high volumes of running in order to complete academy. Deficiencies in either of these qualities may increase the risk of not only academy separation $[11,12]$, but also injury $[9,35,36]$. However, what should be noted is that high running mileages can predispose certain individuals to injury [35]. If a less fit recruit greatly increases their running volume in the weeks preceding academy, this could put them at greater risk of sustaining an overuse injury $[37,38]$. These types of injuries could be mediated if recruits who need to improve their aerobic fitness had access to specific pre-academy strength and conditioning programs and coaching, with appropriate periodization of volume and intensity. 
The other running test adopted by this agency was the 75PR. Lockie et al. [11] found that recruits who separated due to poor fitness or injury were slower in the 75PR compared to recruits who graduated. Both GRAD and SEP recruits improved 75PR from hiring to academy, and there were no significant between-group differences in the change score. Further, GRAD recruits were faster both during initial hiring, and at the start of academy. The 75PR was designed to be a foot pursuit simulation [27], and provided a measure of change-of-direction speed [13, 21, 25]. Contributing factors to change-of-direction speed include linear sprinting ability, movement technique, and lower-body strength and power [39]. Strength, power, and linear and change-ofdirection speed could be enhanced in recruits during the pre-academy process if there is access to specific programs and coaching from strength and conditioning professionals.

GRAD and SEP recruits improved push-up and arm ergometer test performance from hiring to academy. GRAD recruits were superior at both time points, and there were no significant differences in the change scores between the groups. Cesario et al. [13] found that the push-up and arm ergometer tests had a significant, small correlation $(r=0.28)$ in male law enforcement recruits. It was suggested by Cesario et al. [13] that the relationship existed as both tests provided a measure of upper-body muscular endurance. It should be noted that there were large standard deviations for the change scores for both the push-up and arm ergometer test in this study. This would suggest there was a wide variation in whether recruits enhanced or decreased their upper-body endurance. Again, access to properly structured strength and conditioning programs for recruits, especially those with poorer upper-body endurance, would seem to be beneficial to improve this physical quality. This is noteworthy given better push-up performance has been linked to academy graduation in law enforcement recruits [12]. 
In contrast, sit-up performance tended to decrease for both GRAD and SEP recruits from hiring to academy. GRAD recruits were superior both during the hiring process and prior to academy, and there were no significant differences in the change scores between these time points (although the standard deviations indicated a wide variety of scores between recruits). While situps are a common test in law enforcement [5, 8, 40-42], other abdominal exercises may be used more frequently in exercise programming. Indeed, general exercise recommendations has tended to move away from the sit-up, and more towards exercises that encourage trunk stability [43, 44]. Nonetheless, the data from this study suggested that both GRAD and SEP recruits experienced a decline in sit-up performance from their initial testing during the hiring process to the start of academy. This is the opposite of what would be wanted by LEA training staff.

Collectively, these data suggest fitter recruits during initial hiring subsequently arrived at academy in better physical condition, while recruits with poorer fitness during the hiring process stayed that way once allocated to their academy class. It would seem beneficial for an agency to target recruits at risk of separation so they could be provided with specific training to improve their fitness, and subsequent opportunity to complete academy. Mandatory participation in training programs has been recommended for new firefighter recruits [45]. However, the legalities of enforcing attendance at pre-academy training when individuals have not yet been hired by an agency make this complicated. At the very least, an agency should encourage their recruits to attend pre-academy training and should ensure they hire appropriate personnel (i.e. strength and conditioning coaches) to administer these programs. This may facilitate greater improvements in fitness during the pre-academy period for recruits, reducing their commensurate risk of injuries. This approach has been successfully trialed in military trainees [46]. Another issue is that candidates may be working at other jobs before they are officially hired by an LEA. If an 
individual's working hours overlap with pre-academy training sessions, this could result in nonattendance. For candidates unable to attend pre-academy training sessions, if strength and conditioning coaches are on staff for a LEA, they could provide specific programs that can be performed off-site prior to academy.

It is also important to note the differences between the sexes. Only $13 \%$ of all male recruits did not graduate academy, while $24 \%$ of the females separated for various reasons. Although many LEAs do not have different entry standards for the sexes as all are expected to have the same job tasks once they graduate academy [11], female law enforcement recruits tend to perform poorer in a variety of fitness tests compared to males [13, 26, 29, 42, 47]. This is an issue for female recruits if an agency adopts a traditional, 'one-size-fits-all' training model, where all recruits are expected to complete the same volume of exercises during physical training $[9,11]$. Many female recruits may be experiencing a load inappropriate for their current fitness, which could increase their injury risk [48]. Specific strength and conditioning for female recruits may be beneficial in optimizing their path through academy, although further research is needed to support this supposition.

There are some study limitations that should be noted. Multiple LEA staff were involved with recording the hiring data, which could affect the results even though all staff followed established protocols for the agency. As the LEA from this study services an area of approximately $10600 \mathrm{~km}^{2}$, fitness tests conducted as part of the hiring process are often held all over the county to provide greater recruitment opportunities. This is standard practice for the LEA, and data collected during this process has been presented in scientific research [13, 21]. Environmental conditions may have varied from when recruits were tested during hiring, to when the fitness tests were performed prior to academy. This limitation is almost unavoidable as testing is conducted year-round, and the agencies' human resources department controls the allocation of candidates to 
academy classes. No control was placed on the training practices of recruits prior to academy, such there is likely a great degree of variation between the individuals measured in this study. However, this is realistically what happens with candidates before they are allocated to a class $[25,26]$, as they are only moving through the hiring process (and not yet an employee of the agency). It is also a limitation that the 2.4-km run was not conducted at the same time as the other fitness tests performed in the week preceding academy. Furthermore and as noted, the presence of training staff during the 2.4-km run may have also influenced the performance of recruits [7]. Nonetheless, given the potential importance of aerobic fitness relative to academy survivability $[11,12,34]$, the researchers wanted to include some measure of this quality in this study. This is why the $2.4-\mathrm{km}$ run, although performed in the first week of academy, was included in this study.

\section{Conclusion}

In conclusion, GRAD and SEP recruits showed trivial-to-moderate improvements in pushups, 75PR, arm ergometer, and the 2.4-km run, and moderate decrements in sit-ups, between testing conducted during initial hiring and at the start of academy training. There were no betweengroup differences in the change in performance for GRAD or SEP recruits. This meant that fitter recruits during the hiring process remained that way through to academy, and less fit recruits generally did not improve their fitness by a substantial amount. This is an issue, as less fit recruit are more likely to separate from academy, and this can incur great costs for a LEA and negatively affect the number of officers available to work. Given these results, agencies should explore preacademy training for their recruits, especially those at greater risk of separation. Specific training programs should ideally be overseen by strength and conditioning coaches that have the knowledge to improve physical qualities such as aerobic fitness, running speed and technique, endurance, 
strength, and power. This would better prepare all recruits for the rigors of academy training, and could potentially reduce the number of recruits who may separate from academy due to fitnessrelated reasons (e.g. physical training failures, injuries, personal reasons associated with training).

\section{Acknowledgements}

The authors would like to thank the training instructors for facilitating this research, and California State University, Fullerton tactical research team for collating the data.

\section{Conflict of Interest}

This study received no external financial assistance. None of the authors have any conflict of interest.

\section{References}

1. Dawes, JJ, Lindsay, K, Bero, J, Elder, C, Kornhauser, C, Holmes, R. Physical fitness characteristics of high vs. low performers on an occupationally specific physical agility test for patrol officers. J Strength Cond Res. 2017; 31(10): 2808-2815.

2. Schram, B, Hinton, B, Orr, R, Pope, R, Norris, G. The perceived effects and comfort of various body armour systems on police officers while performing occupational tasks. Ann Occup Environ Med. 2018; 30(1): 15.

3. Schram, B, Orr, R, Pope, R, Hinton, B, Norris, G. Comparing the effects of different body armor systems on the occupational performance of police officers. Int J Environ Res Public Health. 2018; 15(5): 893. 
4. Decker, A, Orr, RM, Pope, R, Hinton, B. Physiological demands of law enforcement occupational tasks in Australian police officers. J Aust Strength Cond. 2016; 24(6): 78-79.

5. Dawes, JJ, Orr, RM, Siekaniec, CL, Vanderwoude, AA, Pope, R. Associations between anthropometric characteristics and physical performance in male law enforcement officers: A retrospective cohort study. Ann Occup Environ Med. 2016; 28: 26.

6. Berg, BL. First day at the police academy: Stress-Reaction-Training as a screening-out technique. J Contemp Crim Justice. 1990; 6(2): 89-105.

7. Lockie, RG, Cesario, KA, Bloodgood, AM, Moreno, MR. Heart rate response to psychological stress: Importance of stress education for law enforcement recruits. TSAC Report. 2018; 51: 4-7.

8. Cocke, C, Dawes, J, Orr, RM. The use of 2 conditioning programs and the fitness characteristics of police academy cadets. J Athl Train. 2016; 51(11): 887-896.

9. Orr, RM, Ford, K, Stierli, M. Implementation of an ability-based training program in police force recruits. J Strength Cond Res. 2016; 30(10): 2781-2787.

10. Lockie, RG, Dawes, JJ, Balfany, K, Gonzales, CE, Beitzel, MM, Dulla, JM, Orr, RM. Physical fitness characteristics that relate to Work Sample Test Battery performance in law enforcement recruits. Int J Environ Res Public Health. 2018; 15(11): 2477.

11. Lockie, RG, Balfany, K, Bloodgood, AM, Moreno, MR, Cesario, KA, Dulla, JM, Dawes, JJ, Orr, RM. The influence of physical fitness on reasons for academy separation in law enforcement recruits. Int J Environ Res Public Health. 2019; 16(3): 372.

12. Shusko, M, Benedetti, L, Korre, M, Eshleman, EJ, Farioli, A, Christophi, CA, Kales, SN. Recruit fitness as a predictor of police academy graduation. Occup Med. 2017; 67(7): 555561. 
13. Cesario, KA, Dulla, JM, Moreno, MR, Bloodgood, AM, Dawes, JJ, Lockie, RG. Relationships between assessments in a physical ability test for law enforcement: Is there redundancy in certain assessments? Int J Exerc Sci. 2018; 11(4): 1063-1073.

14. Cooper Institute. Frequently Asked Questions Regarding Fitness Standards in Law Enforcement; 2014. [cited 2019 April 1]. Available from: https://www.cooperinstitute.org/vault/2440/web/files/684.pdf.

15. Los Angeles Police Department. LAPD Candidate Seven Step Process; 2019 [cited 2019 April 23]. Available from: https://www.joinlapd.com/apply/apply-now.

16. Los Angeles County Sheriff's Department. Application Process; 2018. [cited 2019 April 23]. Available from: https://careers.lasd.org/essential_grid/application-process/.

17. Orr, RM. The Royal Military College of Duntroon. Physical Conditioning Optimisation Review - Project Report. 2010. Canberra, ACT, Australia: Royal Military College of Australia.

18. Kaste, M. America's Growing Cop Shortage; 2018. [cited 2019 July 5]. Available from: https://www.npr.org/2018/12/12/675359781/americas-growing-cop-shortage.

19. Roufa, T. Why Police Departments Are Facing Recruitment Problems; 2018. [cited 2019 July 5]. Available from: https://www.thebalancecareers.com/why-police-departments-arefacing-recruitment-problems-974771.

20. Lockie, RG, Moreno, MR, Cesario, KA, McGuire, MB, Dawes, JJ, Orr, RM, Dulla, JM. The effects of aerobic fitness on day one physical training session completion in law enforcement recruits. J Trainol. 2019; 8(1): 1-4.

21. Lockie, RG, Stierli, M, Dawes, JJ, Cesario, KA, Moreno, MR, Bloodgood, AM, Orr, RM, Dulla, JM. Are there similarities in physical fitness characteristics of successful candidates 
attending law enforcement training regardless of training cohort? J Trainol. 2018; 7(1): 59.

22. Lockie, RG, Fazilat, B, Dulla, JM, Stierli, M, Orr, RM, Dawes, JJ, Pakdamanian, K. A retrospective and comparative analysis of the physical fitness of custody assistant classes prior to academy training. Sport Exerc Med Open J. 2018; 4(1): 44-51.

23. Los Angeles County Sheriff’s Department. Pre-Academy Training Classes; 2017. [cited 2019 $\begin{array}{lll}\text { April 23]. Available } & \text { from: }\end{array}$ http://shq.lasdnews.net/content/uoa/PER/PreAcademyWorkout-info.pdf.

24. Los Angeles Police Department. Candidate Advancement Program (CAP); 2019. [cited 2019 April 23]. Available from: http://joinlapd-d7-prod.us-west2.elasticbeanstalk.com/sites/default/files/CAP Flyer.pdf.

25. Lockie, RG, Ruvalcaba, TR, Stierli, M, Dulla, JM, Dawes, JJ, Orr, RM. Waist circumference and waist-to-hip ratio in law enforcement agency recruits: Relationship to performance in physical fitness tests. J Strength Cond Res. 2020; 34(6): 1666-1675.

26. Lockie, RG, Dawes, JJ, Orr, RM, Stierli, M, Dulla, JM, Orjalo, AJ. An analysis of the effects of sex and age on upper- and lower-body power for law enforcement agency recruits prior to academy training. J Strength Cond Res. 2018; 32(7): 1968-1974.

27. Los Angeles County Sheriff's Department. Validated Physical Ability Test; 2018. [cited 2019 March 10]. Available from: https://careers.lasd.org/physical-ability-test/.

28. Burger, SC, Bertram, SR, Stewart, RI. Assessment of the $2.4 \mathrm{~km}$ run as a predictor of aerobic capacity. S Afr Med J. 1990; 78(6): 327-329. 
29. Lockie, RG, Dawes, JJ, Orr, RM, Dulla, JM. Recruit fitness standards from a large law enforcement agency: Between-class comparisons, percentile rankings, and implications for physical training. J Strength Cond Res. 2020; 34(4): 934-941.

30. Lockie, RG, Schultz, AB, Callaghan, SJ, Jeffriess, MD. The effects of traditional and enforced stopping speed and agility training on multidirectional speed and athletic performance. $\mathrm{J}$ Strength Cond Res. 2014; 28(6): 1538-1551.

31. Hopkins, WG. How to interpret changes in an athletic performance test. Sportscience. 2004; 8: $1-7$.

32. Pope, RP, Herbert, R, Kirwan, JD, Graham, BJ. Predicting attrition in basic military training. Mil Med. 1999; 164(10): 710-714.

33. Orr, R, Pope, R, Peterson, S, Hinton, B, Stierli, M. Leg power as an indicator of risk of injury or illness in police recruits. Int J Environ Res Public Health. 2016; 13(2): 237.

34. Dawes, JJ, Lockie, RG, Orr, RM, Kornhauser, C, Holmes, RJ. Initial fitness testing scores as a predictor of police academy graduation. J Aust Strength Cond. 2019; 27(4): 30-37.

35. Trank, TV, Ryman, DH, Minagawa, RY, Trone, DW, Shaffer, RA. Running mileage, movement mileage, and fitness in male U.S. Navy recruits. Med Sci Sports Exerc. 2001; 33(6): 1033-1038.

36. Knapik, JJ, Grier, T, Spiess, A, Swedler, DI, Hauret, KG, Graham, B, Yoder, J, Jones, BH. Injury rates and injury risk factors among Federal Bureau of Investigation new agent trainees. BMC Public Health. 2011; 11(1): 920.

37. Ballas, MT, Tytko, J, Cookson, D. Common overuse running injuries: diagnosis and management. Am Fam Physician. 1997; 55(7): 2473-2484. 
38. Ross, RA, Allsopp, A. Stress fractures in Royal Marines recruits. Mil Med. 2002; 167(7): 560565.

39. Sheppard, JM, Young, WB. Agility literature review: Classifications, training and testing. J Sports Sci. 2006; 24(9): 919-932.

40. Lockie, RG, Dawes, JJ, Kornhauser, CL, Holmes, RJ. Cross-sectional and retrospective cohort analysis of the effects of age on flexibility, strength endurance, lower-body power, and aerobic fitness in law enforcement officers. J Strength Cond Res. 2019; 33(2): 451-458.

41. Dawes, JJ, Orr, RM, Flores, RR, Lockie, RG, Kornhauser, C, Holmes, R. A physical fitness profile of state highway patrol officers by gender and age. Ann Occup Environ Med. 2017; 29(16): 16 .

42. Lockie, RG, Orr, RM, Stierli, M, Cesario, KA, Moreno, MR, Bloodgood, AM, Dulla, JM, Dawes, JJ. The physical characteristics by sex and age for custody assistants from a law enforcement agency. J Strength Cond Res. 2019; 33(8): 2223-2232.

43. Akuthota, V, Ferreiro, A, Moore, T, Fredericson, M. Core stability exercise principles. Curr Sports Med Rep. 2008; 7(1): 39-44.

44. McGill, S. Core training: Evidence translating to better performance and injury prevention. Strength Cond J. 2010; 32(3): 33-46.

45. Roberts, MA, O'Dea, J, Boyce, A, Mannix, ET. Fitness levels of firefighter recruits before and after a supervised exercise training program. J Strength Cond Res. 2002; 16(2): 271-277.

46. Knapik, J, Darakjy, S, G. Hauret, K, Canada, S, Marin, R, Scott, S, Palkoska, F, VanCamp, S, Rieger, W, Jones, B. Effect of pre-conditioning on attrition, fitness, and injuries in army basic combat training. Med Sci Sports Exerc. 2004; 36(5): S308. 
47. Lockie, RG, Hernandez, JA, Moreno, MR, Dulla, JM, Dawes, JJ, Orr, RM. 2.4-km run and 20-m multistage fitness test relationships in law enforcement recruits after academy training. J Strength Cond Res. 2020; 34(4): 942-945.

48. Knapik, JJ, Sharp, MA, Canham-Chervak, M, Hauret, K, Patton, JF, Jones, BH. Risk factors for training-related injuries among men and women in basic combat training. Med Sci Sports Exerc. 2001; 33(6): 946-954. 


\section{Table 1}

Age, height, and body mass at the start of academy for the law enforcement recruits who graduated (GRAD) or separated (SEP) from academy.

\begin{tabular}{cccc}
\hline & Age (years) & Height $(\mathrm{m})$ & Body Mass (kg) \\
\hline GRAD & $26.6 \pm 5.3$ & $1.73 \pm 0.09$ & $80.1 \pm 13.0$ \\
All $(\mathrm{n}=436)$ & $26.6 \pm 5.3$ & $1.75 \pm 0.07$ & $83.2 \pm 11.5$ \\
Males $(\mathrm{n}=362)$ & $26.7 \pm 5.0$ & $1.63 \pm 0.06$ & $64.8 \pm 8.2$ \\
Females $(\mathrm{n}=74)$ & & \\
SEP & $31.8 \pm 10.1 *$ & $1.71 \pm 0.09$ & $75.8 \pm 14.7 *$ \\
All $(\mathrm{n}=78)$ & $32.3 \pm 9.2^{*}$ & $1.74 \pm 0.07$ & $61.7 \pm 6.2$ \\
Males $(\mathrm{n}=55)$ & $30.5 \pm 12.0$ & $1.64 \pm 0.07$ & \\
Females $(\mathrm{n}=23)$ & & & \\
\hline
\end{tabular}

* Significantly $(p<0.05)$ different from the GRAD group. 
Table 2

Descriptive data (mean $\pm \mathrm{SD}$ ) for push-ups, sit-ups, 75PR, arm ergometer, and 2.4-km run from initial hiring to academy in law enforcement recruits who graduated (GRAD) or separated (SEP) from academy.

\begin{tabular}{|c|c|c|c|c|}
\hline & \multicolumn{2}{|c|}{$\begin{array}{l}\text { GRAD } \\
(n=436)\end{array}$} & \multicolumn{2}{|c|}{$\begin{array}{c}\text { SEP } \\
(\mathrm{n}=78 ; \mathrm{n}=50 \text { for the } 2.4-\mathrm{km} \text { run })\end{array}$} \\
\hline & Hiring & Academy & Hiring & Academy \\
\hline $\begin{array}{l}\text { Push-ups } \\
\text { (repetitions) }\end{array}$ & $40.32 \pm 14.25$ & $42.96 \pm 14.77 * \S$ & $33.24 \pm 11.88$ & $35.36 \pm 13.43 * \S$ \\
\hline $\begin{array}{l}\text { Sit-ups } \\
\text { (repetitions) }\end{array}$ & $39.94 \pm 9.15$ & $32.75 \pm 13.17 * \S$ & $37.55 \pm 7.83$ & $30.23 \pm 11.53 * \S$ \\
\hline $\begin{array}{l}75 \mathrm{PR} \\
(\mathrm{s})\end{array}$ & $17.49 \pm 1.27$ & $17.06 \pm 1.30 * \S$ & $18.04 \pm 1.24$ & $17.82 \pm 1.10^{*} \S$ \\
\hline $\begin{array}{l}\text { Arm Ergometer } \\
\text { (revolutions) }\end{array}$ & $127.41 \pm 19.57$ & $133.41 \pm 19.59 * \S$ & $117.54 \pm 17.95$ & $121.16 \pm 21.65 * \S$ \\
\hline $\begin{array}{l}\text { 2.4-km Run } \\
\text { (min:s) }\end{array}$ & $12: 49 \pm 1: 32$ & $11: 55 \pm 1: 25^{*} \S$ & $13: 44 \pm 1: 27$ & $13: 17 \pm 1: 12 * \S$ \\
\hline
\end{tabular}


Table 3

Change in scores (mean $\pm \mathrm{SD}$ ) and effect size $(d)$ for push-ups, sit-ups, 75PR, arm ergometer, and 2.4-km run from initial hiring to academy in law enforcement recruits who graduated (GRAD) or separated (SEP) from academy.

\begin{tabular}{|c|c|c|c|c|}
\hline & \multicolumn{2}{|c|}{$\begin{array}{c}\text { GRAD } \\
(n=436)\end{array}$} & \multicolumn{2}{|c|}{ SEP } \\
\hline & Difference & $d$ & Difference & $d$ \\
\hline $\begin{array}{l}\text { Push-ups } \\
\text { (repetitions) }\end{array}$ & $2.64 \pm 11.83$ & 0.18 & $2.12 \pm 10.93$ & 0.17 \\
\hline $\begin{array}{c}\text { Sit-ups } \\
\text { (repetitions) }\end{array}$ & $-7.09 \pm 13.09$ & 0.63 & $-7.32 \pm 10.91$ & 0.74 \\
\hline $\begin{array}{l}75 \mathrm{PR} \\
(\mathrm{s})\end{array}$ & $-0.42 \pm 1.05$ & 0.33 & $-0.23 \pm 0.94$ & 0.19 \\
\hline $\begin{array}{c}\text { Arm Ergometer } \\
\text { (revolutions) }\end{array}$ & $5.56 \pm 23.72$ & 0.31 & $3.57 \pm 19.75$ & 0.18 \\
\hline $\begin{array}{l}\text { 2.4-km Run } \\
\text { (min:s) }\end{array}$ & $-0: 50 \pm 1: 28$ & 0.61 & $-0: 36 \pm 1: 18$ & 0.34 \\
\hline
\end{tabular}




\section{Figure 1}

The dimensions for the 75PR in meters (m; A) and the running direction (numbered in order; B). The barriers were $2.44 \mathrm{~m}$ long and $0.15 \mathrm{~m}$ high.
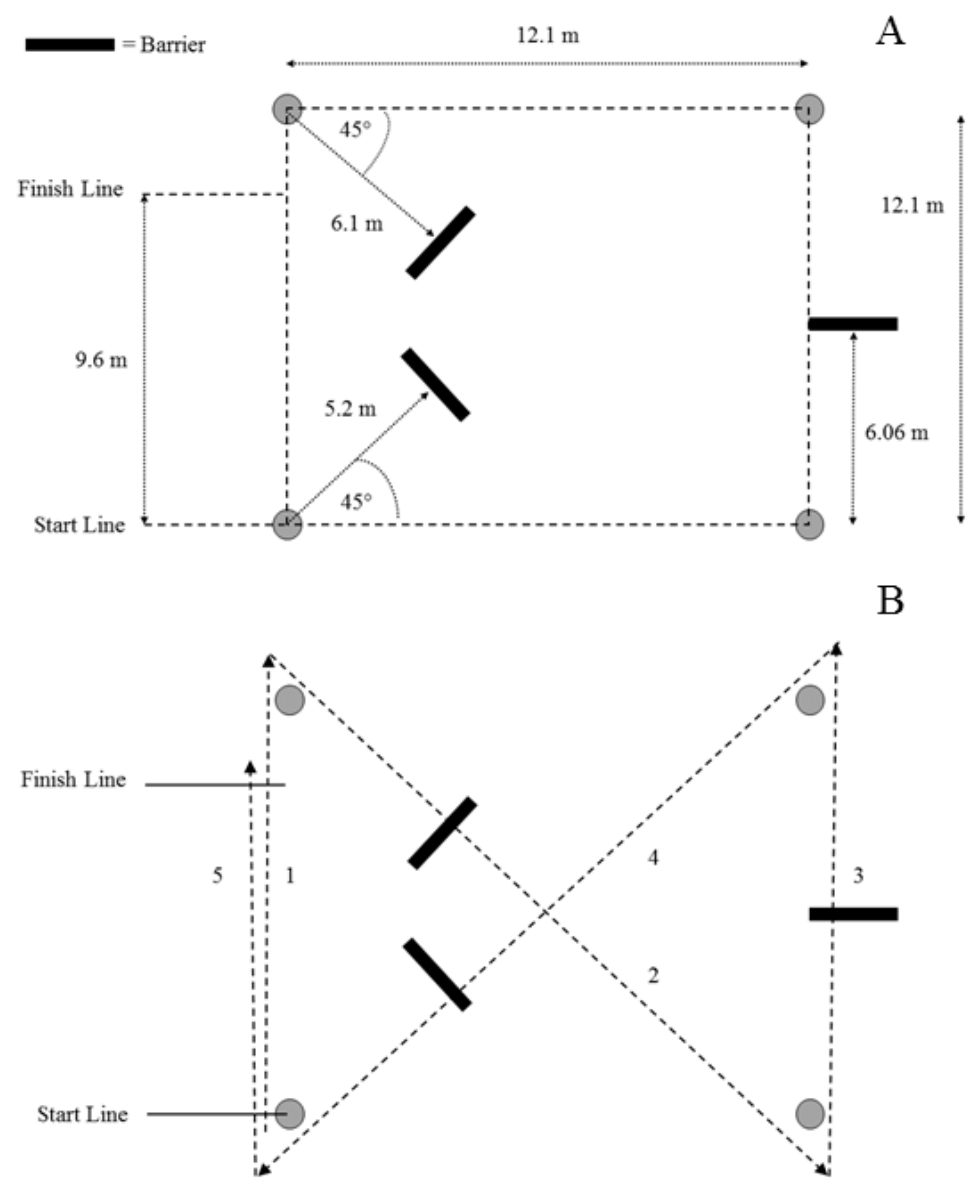